\title{
Mercados ilegais, redes de proteção e organização local do crime no Rio de Janeiro
}

\section{MICHEL MISSE}

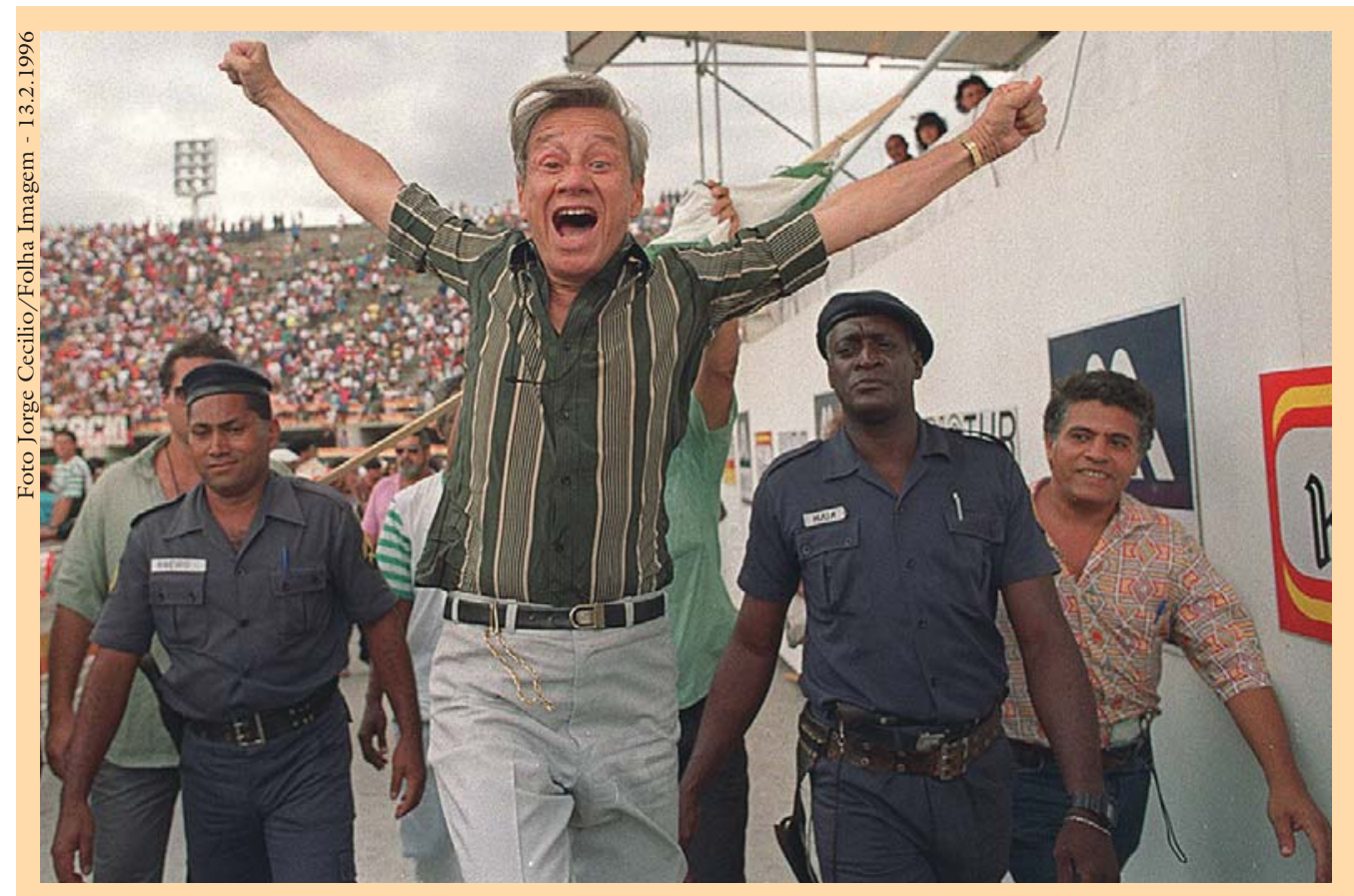

Patrono da Mocidade Independente de Padre Miguel, o banqueiro do jogo do bicho Castor de Andrade (1926-1997), durante apuração das escolas de samba no Sambódromo carioca.

ENHO procurado enfatizar a necessidade de se diferenciar a criminalização conceitual, tal como se inscreve nos Códigos Penais e na representação social, da incriminação real, porque tenho observado, em minhas pesquisas de campo, que atividades tipificadas institucionalmente como delituosas ou criminosas são, muitas vezes, tratadas como distintas das atividades envolvidas em mercados informais. Do mesmo modo, há mercados informais tratados como "legais" e mercados informais para os quais se reserva o peso preferencial da criminalização, os “ilegais".

Com isso, pretendo enfatizar a variedade das situações que podem ou não ser objeto de incriminação preferencial nos chamados mercados informais. Assim, é porque ocorre a criminalização preferencial de uma parte dos mercados 
informais e também é porque ocorrem incriminações preferenciais de certos agentes desses mercados e não de outros que podemos: 1. distinguir sociologicamente o que é tratado, nas práticas sociais, como delito ou crime do que é tratado tolerantemente apenas como mercado informal ou ilegal; 2 . distinguir o tratamento que é dado a trocas toleradas e não-toleradas como: mercadorias lícitas e vendidas no mercado formal, mercadorias lícitas e vendidas no mercado informal, mercadorias lícitas de venda regulamentada vendidas ilicitamente no mercado formal, mercadorias ilícitas vendidas no mercado informal.

É para este último grupo que geralmente se reserva a expressão "mercado ilegal" e não a todo o grupo de ilegalismos e delitos, sejam os do mercado legal sejam os do informal, ou do ilegal (que reúne informalidade e ilegalidade da mercadoria). O contrabando de bebidas alcoólicas, por exemplo, distingue-se, para muitos, do tráfico de drogas; o "mercado negro" de mercadorias nãocriminalizadas, mas escassas ou de venda regulada, ganha status diferencial em relação ao contrabando de importados sem imposto; a pirataria de compact discs recebe tratamento diferente do mercado informal de adoções de bebês; a exploração empresarial da prostituição não provoca a mesma reação moral que provoca o "tráfico de mulheres"; a corrupção policial provoca maior reação moral que a lavagem de dinheiro por grandes organizações financeiras; a espionagem industrial e o roubo de patentes produzem menos interesse criminalizador que o batedor de carteiras nas ruas e o fraudador de documentos bancários. Esses exemplos não esgotam, evidentemente, a variedade e multiplicidade de combinações possíveis entre delitos e formas de troca, entre crimes e mercados.

Entender como diferentes setores da sociedade separam e distinguem - dentro ou por fora dos códigos criminais - o que pode e o que não pode ser tolerado numa relação de troca, mas que se evita trocar, do que é intolerável trocar, mas que se troca mesmo assim, esse tem sido um dos objetivos a que tenho me proposto em meus recentes estudos sobre esse tema no Brasil (Misse, 1997, 1999, 2005, 2006). Isso deriva da constatação de que no Brasil, ou em algumas grandes cidades brasileiras como o Rio de Janeiro, essas trocas tenham se tornado de algum modo tão freqüentes e tão importantes na vida das pessoas, que não há mais como continuar a tratá-las exclusivamente de uma perspectiva moral, que incorpora sua criminalização legal. Quando se trata, então, de classificá-las como "Crime Organizado", interligando níveis distintos de reação moral a um mesmo grupo de fenômenos, então o nosso problema complica-se ainda mais.

\section{Crime Organizado e mercados informais e ilegais}

A noção de "Crime Organizado" esconde mais do que revela as pequenas nuanças e as grandes diferenças da diversidade de atores, redes e práticas que caem sob a acusação social (e o respectivo processo de incriminação) por infringir, regular e articuladamente, artigos do Código Penal e de Leis Especiais. Pois que a variedade dos crimes e de seus contextos produz tal diversidade de 
organizações sociais possíveis de cometê-los que aglutinar numa só expressão essa multiplicidade conduz geralmente a grandes equívocos. O que se pretende, afinal? Distinguir organizações criminais de crimes convencionais individualizados? Distinguir a articulação social de grupos criminosos daqueles faits divers da crônica cotidiana da imprensa? O uso metonímico do termo "máfia” incide a tal ponto nos mesmos problemas, que aquilo que no Código Penal é tipificado simplesmente como "formação de quadrilha" (e que também serve para coisas muito diferentes) termina sendo, de qualquer maneira, uma "máfia” qualquer mesmo. ${ }^{1}$

De todo modo, a noção termina sendo tão empregada que os contextos de seu uso acabam por delimitar o sentido do que se está querendo dizer, o que oculta na prática e no cotidiano a inevitável polissemia da noção. E, no entanto, sabemos que qualquer ladrão que pratica seu ofício sistematicamente precisa de receptadores, que seus contatos com esses exigem algum grau de articulação e que todos, por sua vez, participam ativamente de redes que comercializam bens furtados ou roubados. Diríamos, no entanto, que esse ladrão participa de uma rede organizada de crimes? Estaria esse ladrão envolvido no "Crime Organizado"? A descentralização das economias ditas "subterrâneas" ou do "capitalismo clandestino" é tão extensa que aos três ou quatro "cartéis" colombianos da droga juntaram-se cerca de cem organizações médias e perto de três mil "pequenos empreendedores" (Labrousse, 2004).

A atividade ilegal de vendedores ambulantes, por exemplo, pode envolver diferentes tipos de mercadorias. No entanto, no Brasil geralmente diferenciamos aqueles que transacionam produtos "piratas" ou contrabandeados daqueles outros que vendem drogas ilícitas: os primeiros são "camelôs" e a acusação social lhes é muito menos severa do que a que recai sobre os que transacionam maconha ou cocaína a varejo, por exemplo. Esses são chamados de "traficantes", o mesmo termo aplicado aos operadores do tráfico internacional. Entre esses, há os que enriquecem participando do comércio atacadista internacional e os que, ainda adolescentes, vendem "papelotes" ou "baseados" para outros adolescentes e jovens. Ainda entre estes últimos, a acusação social parece privilegiar mais aqueles que operam nas favelas, conjuntos habitacionais de baixa renda ou bairros periféricos das grandes cidades brasileiras do que os que agem com base em agendas telefônicas e redes de relações de confiança entre usuários da mesma classe média de onde provêm, moradores de apartamentos e casas de bairros de renda média ou alta. Nesse caso, o que parece demarcar a diferença não é tanto o tipo de mercadoria ou a rede de comercialização, mas os efeitos diferenciais de violência que seu comércio pode produzir.

Finalmente, há os que reservam a designação de "Crime Organizado" principalmente para o tipo de organização criminosa que é capaz de cooptar agentes do Estado e, desse modo, tornar-se quase invulnerável à ação repressiva da lei. No entanto, é difícil distinguir onde há cooptação e onde há apenas mais 
um mercado ilegal, um mercado que transaciona mercadorias políticas (Misse, 2006) e que, como tal, não se distinguiria de nenhum outro mercado ilegal, a não ser pelo fato de que "oferece" uma mercadoria muito especial, constituída por relações de força e poder ou extraída simplesmente da autoridade pública, como uma fração privatizada e mercantilizada da soberania do Estado.

\section{O jogo do bicho}

Até que o " movimento" (tráfico de drogas a varejo nas favelas cariocas) se transformasse no principal foco de interesse da segurança pública no Rio de Janeiro, o "jogo do bicho" foi o mercado ilícito mais importante, tradicional e poderoso. Sua capacidade de atração de força de trabalho proveniente do "submundo" criminal sempre foi grande, principalmente oferecendo emprego e proteção a ex-presidiários. Foi também durante muito tempo uma alternativa de ganho para crianças e adolescentes pobres, que eram recrutados como "olheiros" dos pontos e "garotos de recado" entre gerentes e apontadores. A estrutura desse mercado permaneceu segmentada em territórios rivais até o final dos anos 1970, quando os principais banqueiros do jogo do bicho no Rio de Janeiro (e em outros Estados) fecharam um acordo que deu origem à atual "cúpula" do jogo do bicho, cujo poder parece estar agora entrando em declínio, com a proliferação de alternativas legais de jogo. Herdeiros atuais de alguns dos banqueiros praticamente substituíram o "bicho" pela disputa pelo controle da distribuição de caça-níqueis em bares e bingos das cidades, com o tradicional apoio de grupos de autoridades policiais, civis e militares. Sua rede social, sua capacidade de dominação e sua expressão política local transformaram o "jogo do bicho", isto é, os "banqueiros" do jogo e seu entorno de agentes, políticos e clientes, durante muito tempo, numa organização algo semelhante à máfia norte-americana do jogo, ainda que em bem menores proporções.

Para que se tenha uma idéia de um dos principais tipos de conflito que caracterizaram a violência na cidade nos anos 1950 e 1960, basta que se recorra - a partir do noticiário jornalístico da época - à série de crimes que foram cometidos em apenas um mês no enfrentamento entre apenas dois "banqueiros" do Rio. O conflito envolveu organização de pistoleiros de cada lado, chamados pela imprensa de "Sindicato do Crime", e as redes familiares de cada banqueiro, no que se tornou uma "sangrenta sucessão de lutas de proporções alarmantes" $(O$ Dia, 26.1.1961).

A estrutura do “jogo do bicho” era (e ainda é) constituída por uma miríade de pontos de venda ("pontos do jogo do bicho") que se confundem com a "presença" de um "apontador". O apostador procura o apontador para fazer seu jogo. Esses ficam em lojas ou em vias públicas, como camelôs, ou semiclandestinos quando a repressão é maior. Nesse caso, pagam a adolescentes alguns trocados para ficarem de "olheiros" e avisarem da chegada da polícia. O apontador recebe comissão sobre os jogos que ele aponta e sobre os prêmios sorteados em seu ponto, mas pode também ser assalariado. Um gerente administra 
vários pontos e apontadores, pode pagar salários a esses e ficar com as comissões, como pode também ser ele próprio assalariado de um "banqueiro". Pode manter ou ter a seu encargo contadores, advogados e um ou mais pistoleiros, para a proteção dos pontos em caso de tentativa de invasão por outros gerentes ou banqueiros.

Geralmente os apontadores não enfrentavam a polícia, durante as "batidas". Sendo uma contravenção, um delito de menor gravidade, o apontador contava com a possibilidade de passar por uma detenção por alguns meses, quando estava certo de que teria a proteção do "banqueiro". O banqueiro é aquele que controla um "território", onde atuam "seus" gerentes, pistoleiros e apontadores. Ele é quem paga o prêmio e recebe o dinheiro das apostas. Ele pode " descarregar" parte das apostas de sua área em outro banqueiro do mesmo nível ou no banqueiro mais rico e poderoso, o "dono" de toda uma área ou município. Com o nome de "Paratodos" (nome que se deu à loteria do Rio a partir do entendimento que levou à constituição da "cúpula"), essa rede de banqueiros se estendeu praticamente a todo o país, sem que cada um dos "donos" perdesse sua autonomia. Um estudo sobre sua atual organização nacional ainda está por ser feito.

Essa mesma estrutura local se reproduz em vários “territórios” e a maior ou menor tensão entre banqueiros (alianças precárias de um lado, conflito aberto de outro) marcou grande parte da história do jogo do bicho neste século no Rio de Janeiro, até que se alcançasse, sob a liderança inconteste de Castor de Andrade, filho de banqueiro dos anos 1940-1950 e seu herdeiro no controle do bicho nos bairros de Bangu e Padre Miguel, uma aliança estável entre todos os principais banqueiros da cidade no início dos anos 1980, chamada de "cúpula do jogo do bicho". A cúpula organizou-se legalmente com a criação da Liga das Escolas de Samba, que passou a dirigir o grande desfile das escolas no carnaval carioca desde então, com a premiação oficial transmitida pelas redes de televisão para todo o país. ${ }^{3}$

A luta pelo controle de pontos e áreas do jogo no Rio de Janeiro, da década de 1940 até o final dos anos 1970, foi um importante fator da representação social da violência na cidade, mas foi a ligação que se estabeleceu entre esse mercado ilícito e a "proteção" policial o principal responsável pela representação crescente de corrupção policial na cidade (ao lado da exploração do lenocínio) até que o " movimento", no início dos anos 1980, passasse a receber a principal atenção. Todos os banqueiros de jogo do bicho e alguns gerentes que enriqueceram mantiveram e mantêm empreendimentos econômicos legais, ao lado de sua atividade ilícita principal. Castor de Andrade, por exemplo, entre outros empreendimentos, chegou a instalar fábrica de processamento de pescados no sul da Bahia, no início dos anos 1970. Há um hotel de cinco estrelas em Niterói que é de propriedade de familiares de um conhecido bicheiro da cidade. Foi construido para se transformar em cassino, caso o jogo seja legalizado no Brasil. 
O que distingue, em geral, uma atividade econômica "formal" de outra “informal” é a sua maior ou menor subordinação à regulamentação estatal. Não se considere, no entanto, que essas atividades são inteiramente separadas, constituindo "setores" bem demarcados. Diferentes formas de "flexibilização" informais participam da constituição de empresas econômicas "formais", e a informalidade ilegal de certas atividades econômicas pode dirigir-se, ao mesmo tempo, para "fachadas" formais ou mesmo mobilizar recursos em empresas legais. Múltiplas e complexas redes sociais se desenvolvem a partir dessas diferentes estratégias aquisitivas, legais e ilegais, relacionando "mundos" que o imaginário moral prefere considerar como inteiramente separados entre si. ${ }^{4}$

Todas essas redes sociais que interligam mercados legais e ilegais, formais e informais, exploração de mercadorias políticas (propinas, chantagens, extorsões, redes de proteção) e exploração ilegal de mercadorias de oferta regulada ou criminalizada (como o jogo, o aborto, a prostituição e as drogas) não adquirem necessariamente contornos espaciais ou comunitários e nem constituem "setores", mas, antes, percorrem complexamente todo o conjunto do tecido social, político e econômico. Quando algum contorno espacial-comunitário se desenha, quando uma "territorialização" pode ser identificada, a questão parece ganhar uma dimensão política completamente diferente daquela que se encontra na criminalidade pulverizada, seja ela convencional ou não. Se, por um lado, essa territorialização reforça estereótipos e estigmatiza importantes segmentos sociais do espaço urbano, por outro, passa a constituir efetivamente novas redes de sociabilidade, que emergem das relações de poder que demarcam esses territórios.

Isso aconteceu com o jogo do bicho, mas ganhou sua expressão mais violenta a partir dos anos 1980 com o aparecimento de redes de traficantes de drogas a varejo instalados em favelas e conjuntos habitacionais do Rio de Janeiro, com base nas antigas, tradicionais e freqüentemente pequenas "bocas de fumo" freqüentadas pelos malandros e marginais que compunham a crônica policial do Rio de Janeiro nas décadas anteriores, no que se cognominava (e ainda se cognomina) de "movimento". Esse é sem dúvida um indicador de que algum grau de organização é necessário para manter o controle sobre os agentes que operam nesses "territórios", bem como para estabelecer relações de troca com os agentes públicos encarregados de reprimi-los.

\section{O "Movimento"}

Movimento é o nome que se deu ao mercado local de drogas - inicialmente a maconha - nas favelas, nos conjuntos habitacionais, nas vilas e em outras áreas da periferia urbana do Rio de Janeiro, habitadas em sua grande maioria por populações de baixa renda. Seja como sinônimo de "boca de fumo" seja como uma ampliação de seu significado original, de "movimento de vendas", a expressão apareceu pela primeira vez como jargão no jogo do bicho. Atualmente, o movimento comparece na gíria de consumidores e vendedores de drogas ilícitas para representar vários e diferentes aspectos desse mercado. 
"Pôr um movimento" significa instalar o comércio num determinado local, como também ocorre na expressão "botar uma boca”. O “movimento fortaleceu” significa tanto que a boca é grande, com grande freguesia, como que a venda e a circulação monetária cresceram num ou vários locais e sua "proteção" é estável. "Aonde que tá o movimento?" é uma pergunta sobre a localização da "boca" e dos vendedores. Raramente a expressão é usada para vendedores individuais ou autônomos, mas para indicar um grupo social num determinado território. "Pôr o movimento na Rocinha", por exemplo, não significa, entretanto, que o grupo que o pôs lá controla toda a favela da Rocinha, mas que há movimento lá, em determinados locais ou pessoas, conhecidos da clientela, em seus vários de pontos-de-venda, que continuam a ser chamados de "bocas de fumo".

A venda ou a guarda de "entorpecentes", no Brasil, jamais foi apenas uma contravenção. Passou a ser criminalizada pelo Código Penal de 1940, no título VIII: “crimes contra a incolumidade pública”, capítulo I: “dos crimes de perigo comum", artigo 281. A pena prevista era de reclusão, de um a cinco anos, além de multa. Em 1968 (Decreto-Lei n.385) e depois em 1971 (Lei n.5.726), alterações foram feitas, introduzindo o processo sumário nos casos de flagrante (a grande maioria) e endurecendo as medidas penais, como o aumento da reclusão para até seis anos, o aumento da multa para até cem salários mínimos e o aumento das penas no caso de a venda ser feita por bando ou quadrilha. Em 1976, nova legislação distingue usuários de traficantes, reservando aos últimos penas mais duras, mas conservando ampla ambigüidade quanto à definição do que seja consumidor e traficante, cabendo à polícia, com total autonomia, o enquadramento num ou noutro tipo. Parece evidente que data, portanto, do final dos anos 1960 o incremento da repressão ao movimento, como pode ser observado no Gráfico 1, que compara dados judiciais e policiais do período 1957-1985.

Curiosamente, o que se observa é que as taxas judiciárias de 1966 são apenas igualadas em 1972 e 1978. O endurecimento das penas, em 1968, encontra uma criminação análoga à de 1962. As taxas policiais são muito próximas das judiciárias em todos os anos em que foi possível comparar as duas séries. $\mathrm{O}$ período em que se considera que aumenta significativamente o tráfico de cocaína (1979-1981) apresenta taxas menores que as de 1966. Apesar de, na lei, até 1976, não existir distinção entre usuários e vendedores, os dados representam toda a fatia do mercado de drogas que foi criminalizada nesse período. O que parece mais importante é a mudança na tendência ascendente da curva a partir de 1966, exatamente no período em que aumenta a visibilidade social do mercado de drogas e, por conseguinte, legislações penais mais duras se sucedem.

A hipótese mais plausível é que a diferença entre a criminação até 1966 (que cresce regularmente e projeta uma tendência) e a criminação posterior a 1966, que inverte a tendência ou, no máximo, a estabiliza numa faixa inferior à taxa de 1966, poderia ser explicada não pelos seus efeitos de dissuação, mas pelo alargamento das transações ilícitas entre policiais e usuários, inicialmente, e depois entre policiais e traficantes. Exatamente no período em que a legislação 
endurece, o mercado ilícito de achaques e propinas torna-se mais atraente, diminuindo o volume de incriminações. Não me parece plausível que esse endurecimento das penas possa ter dissuadido consumidores e vendedores pela simples razão de que uma nova mudança na legislação, ainda mais dura, decretada em 1980, não impedirá a tendência de aumento da criminação do movimento nos anos 1982-1985, um período em que também aumenta a incriminação de policiais acusados de exigir propinas de acusados por tráfico de entorpecentes. ${ }^{5}$

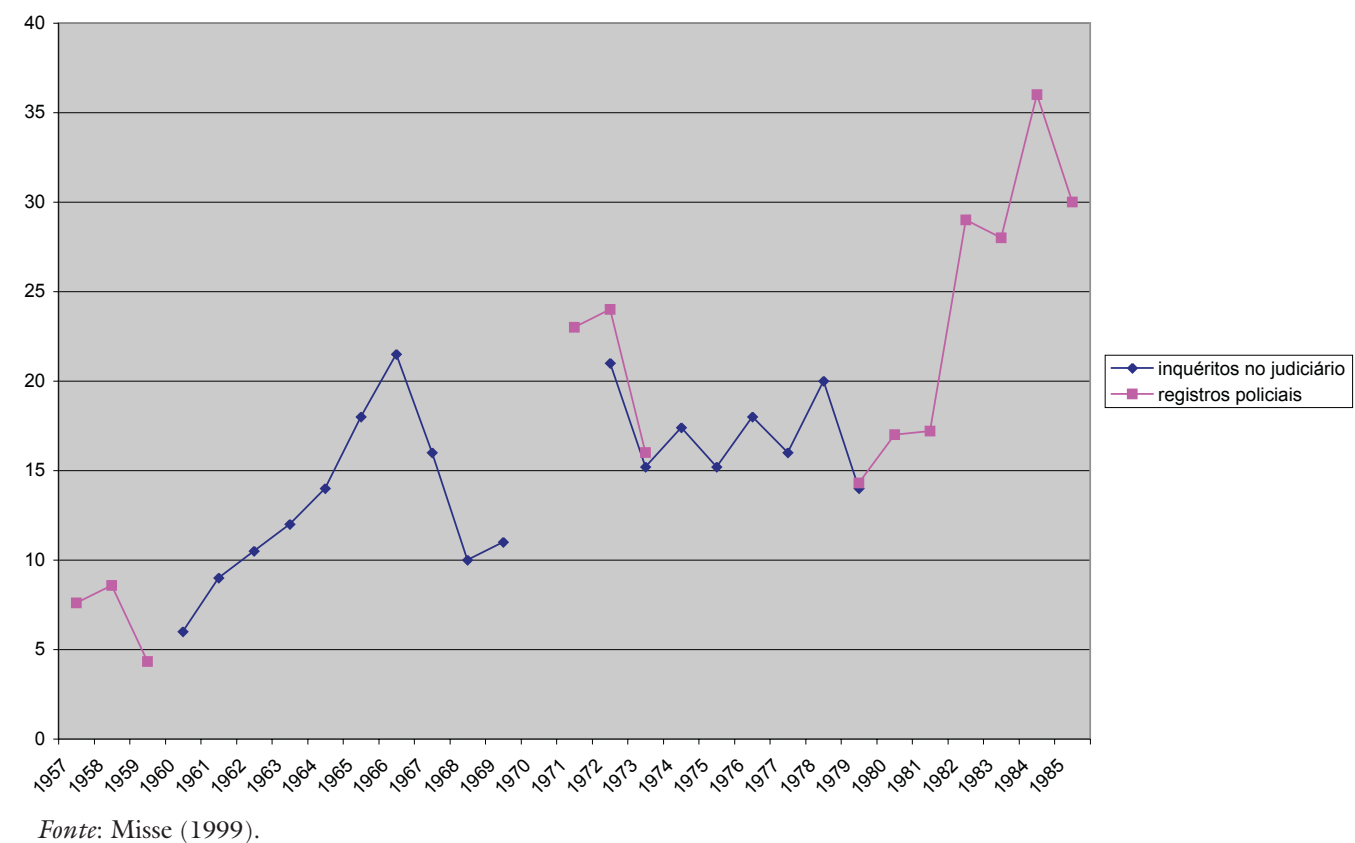

Gráfico 1

Registros judiciários e policiais de ocorrências com entorpecentes (comércio e posse) no Rio de Janeiro, capital (1967-1985). Taxa por cem mil habitantes.

A partir de 1987, as taxas caem abruptamente, e entre 1989 e 1993 o volume de incriminação por entorpecentes deixa de ser incluído nos Relatórios Anuais da Secretaria de Segurança Pública, aparentemente sobrepujado pela mobilização do interesse estatístico da Secretaria de Segurança para o grande aumento de homicídios dolosos e outros crimes violentos na cidade. Entretanto, desde o final dos anos 1970 existem dados oficiais que distinguem registros policiais por uso de drogas dos registros por tráfico, o que permite desagregar os dados de incriminação apresentados no Gráfico 1, em alguns anos (Gráfico 2).

Fica evidenciado que havia menor incriminação pelo porte (ou uso) de entorpecente em 1977 (e talvez antes), em comparação com os anos seguintes, quando haverá maior incriminação relativa, mas o tráfico voltará a ser o principal incriminado em meados da década de 1990. Outro indicador relevante do crescimento vertical do "movimento" é o volume de apreensões de drogas nos anos em que esses dados foram contabilizados, bem como o crescente comparecimento da cocaína entre as drogas apreendidas. 


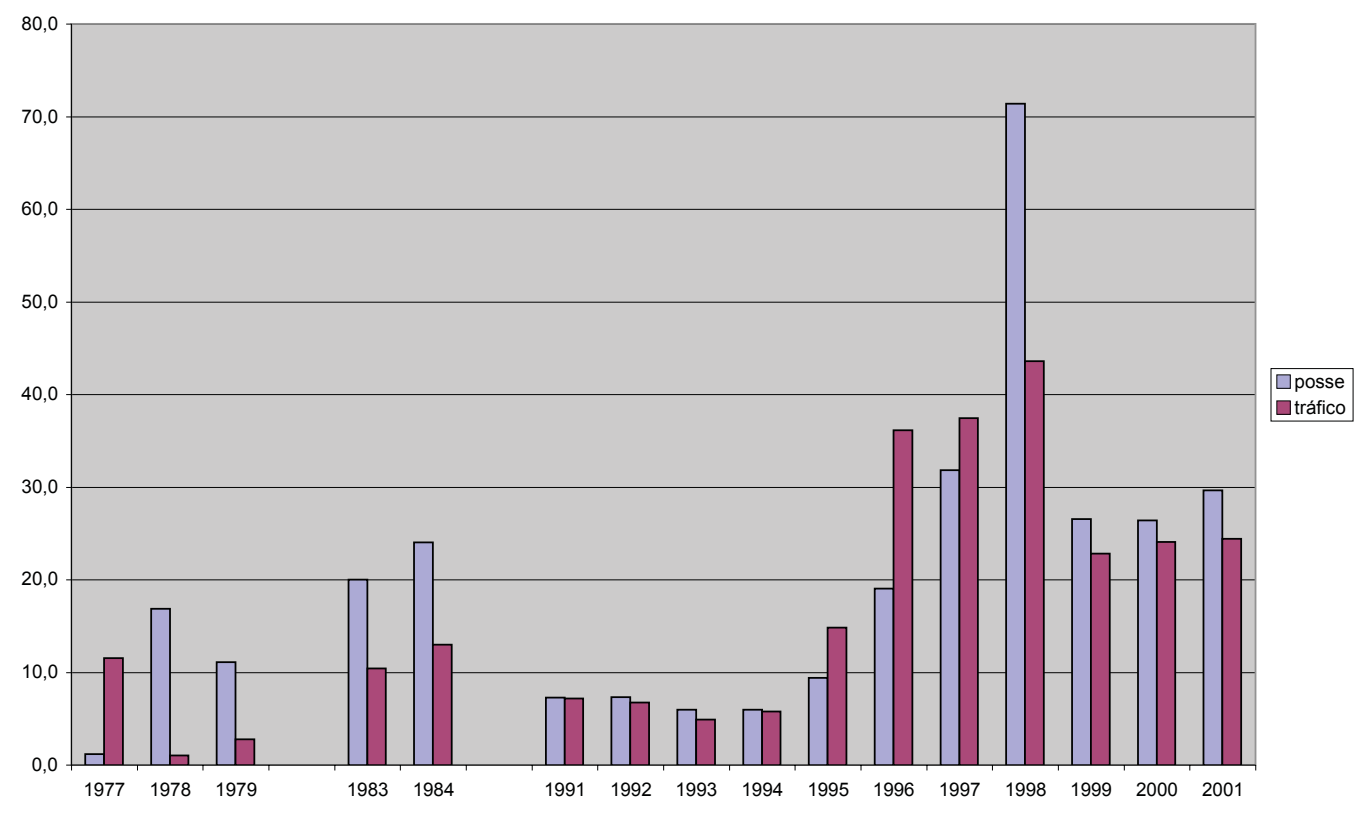

Fonte: Polícia Civil do Estado do Rio de Janeiro.

Gráfico 2

Flagrantes de posses e tráfico de entorpecentes na cidade do Rio de Janeiro, em alguns anos, entre 1977 e 2001. Taxa por cem mil habitantes.

\section{Dos assaltos ao tráfico: a constituição das redes ("comandos")}

O que fez a classe média carioca, desde o início dos anos 1970, se cercar em seus prédios e condomínios não foi inicialmente provocado pelo desenvolvimento do tráfico de drogas nas áreas urbanas pobres da cidade, mas decorreu do aumento dos assaltos, com ou sem arrombamento, de bancos, carros, residências e apartamentos, bem como dos furtos e assaltos nas ruas antes que o tráfico de cocaína se implantasse. Embora esse aumento da criminalidade convencional vá se associar, a partir de meados dos anos 1980, ao crescimento do tráfico, ainda está para ser demonstrado que o "medo da violência", no Rio, começou apenas a partir do tráfico. A maioria dos analistas concorda que a "sensação de insegurança" na cidade se instalou a partir do final dos anos 1970, mas uma breve leitura dos jornais de época demonstra que o problema já se colocava antes, na primeira metade da década.

Não existem estatísticas de fonte policial razoavelmente confiáveis para o período anterior a 1977, mas é significativo que, na área da delinqüência juvenil, para a qual existem estatísticas judiciárias desde o início dos anos 1960 até hoje, se verifique uma extraordinária mudança de padrão de infrações contra o patrimônio a partir da primeira metade dos anos 1970. O furto, infração amplamente dominante por décadas até o início dos anos 1970, vai sendo substituído tendencialmente pelo roubo, a partir do mesmo período até ultrapassá-lo no mesmo qüinqüênio (1995/1999) em que a posse e o tráfico de drogas superam extraordinariamente todas as outras curvas, indicando a migração do investi- 
mento dos adolescentes infratores do furto para o roubo e para o porte e tráfico de drogas (Gráfico 3).

Esse qüinqüênio assinala também a juvenilização da mão-de-obra envolvida no tráfico, em virtude das sucessivas prisões e mortes dos traficantes da geração anterior. A mesma tendência - aumento do roubo em relação ao furto e crescimento sistemático do envolvimento com drogas ilícitas - verificada entre crianças e adolescentes entre 1960 e 2004 pode ser observada, também no mesmo período, para a criminalidade convencional de adultos - o aumento regular e sistemático dos assaltos e do roubo (a residências, a veículos e a instituições financeiras). Essa mudança de padrão ocorre, grosso modo, na primeira metade dos anos 1970, associando-se ou substituindo-se, em seguida, ao crescimento do mercado, mais lucrativo e ainda menos arriscado, do tráfico de cocaína.

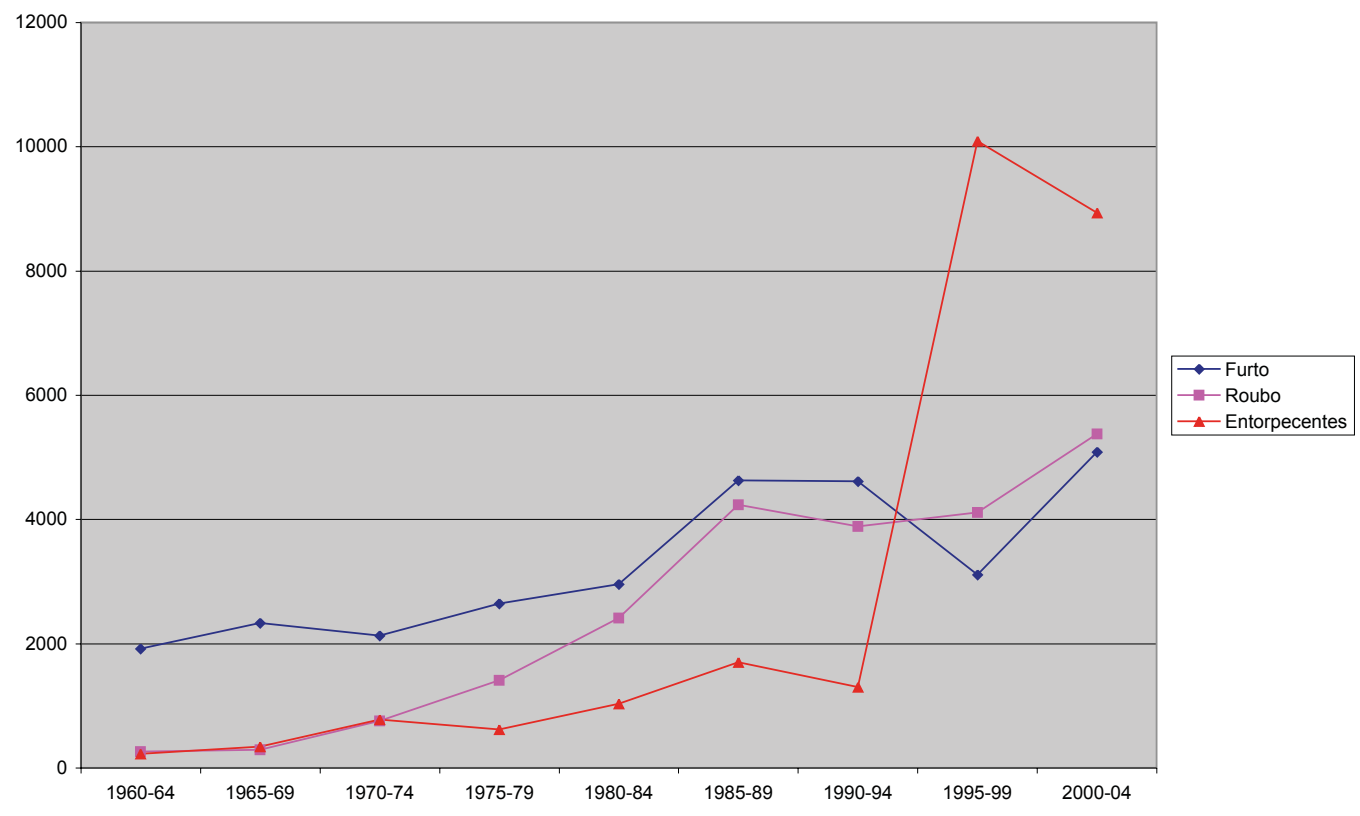

Fonte: Juizado de Menores da Cidade do Rio de Janeiro. Obs.: Os dados de roubo incluem também latrocínio.

Gráfico 3

Crianças e adolescentes acusados por furto, roubo e entorpecentes (posse e tráfico). Rio de Janeiro, capital. Qüinqüênios: 1960-2004.

É bastante plausível a hipótese de que houve uma mudança de investimento criminal, muitas vezes entre os mesmos agentes criminais, que levou dos assaltos a bancos e residências ao tráfico de drogas, num período de dez anos, e a um reforço posterior dos assaltos em associação ou não com o tráfico. Do ponto de vista econômico, a opção entre a transação dessas diferentes mercadorias criminalizadas (bens roubados e drogas) oscilou provavelmente, seguindo uma avaliação de custo/benefício, em razão das relações com segmentos das bases policiais envolvidos nas políticas de repressão adotadas em diferentes conjunturas desse período. 
Uma análise de custos, nesse caso, não deve subestimar os efeitos econômicos da dimensão moral envolvida na comparação entre negociar com "assaltantes", com "bicheiros" ou com "gerentes do tráfico”. A famosa frase de Lúcio Flavio Villar Lírio, chefe de uma quadrilha de assaltantes de bancos desmantelada no início dos anos 1970: "bandido é bandido, polícia é polícia”, dirigia-se exatamente à já enorme confusão de papéis que resultava da sobreposição de mercados que transacionavam mercadorias ilegais de diferentes tipos. ${ }^{6}$

Até a década de 1980, o mercado informal ilegal no Rio de Janeiro era dominado pelo jogo do bicho. Somente a partir do final dos anos 1970 é que o tráfico de cocaína começa a ser detectado em grande escala no Rio, e sua importância só se consolidará no período em que esse foi efetivamente controlado pela rede de quadrilhas denominada pela imprensa de "Comando Vermelho" (aproximadamente entre 1984 e 1986). O período seguinte, caracterizado pela decadência do "controle externo" do "Comando" sobre muitas áreas do tráfico e a segmentação dos territórios, com constante guerra entre diferentes grupos do "movimento", continua até hoje, mas atingiu o seu ápice entre 1987 e 1994. É a fase mais violenta, marcada pelo extraordinário aumento da desconfiança entre lideranças e grupos, pelas lutas intestinas pela liderança no interior de um mesmo território ou entre territórios diferentes e pelo aumento da repressão policial violenta (principalmente a partir de 1994). Seu principal resultado foi a entrada maciça de crianças e adolescentes no tráfico, a partir daquele ano, e o conseqüente aumento de mortes nessa faixa etária.

Ao se estudar de perto uma "boca" do "movimento", pode-se tentar esboçar algumas linhas dos tipos de interação (Zaluar, 1995; Souza, 1996; Misse, 1997; Dowdney, 2003) que constituem as redes do mercado informal ilegal em muitas comunidades de pobreza urbana carioca. Os chamados "comandos" do tráfico no Rio são redes constituídas pelos acordos (tácitos, precários) entre “donos” de várias áreas de varejo (algumas de distribuição para o varejo de áreas menores), quase todos cumprindo penas nos presídios de segurança máxima do Rio de Janeiro (Bangu I, II, III). Dirigem suas "ordens" para seus "gerentes", mas esses encontram dificuldades para uma articulação "extramuros" do sistema penitenciário, em razão do que chamam de "olho grande", isto é, exatamente a ausência de organização capaz de oferecer proteção e confiança e controlar as ambições dos diversos operadores das quadrilhas de varejo, que disputam o controle local. Na ausência dessa organização, as redes “extramuros" são frágeis e vulneráveis à extorsão policial. No entanto, são mantidas sob a proteção do mesmo "sistema" encarregado de reprimi-las, forçando-as a comprar suas "mercadorias políticas".

A estruturação do "movimento" em redes começou com o "Comando Vermelho", mas atravessou diferentes etapas, mantendo no entanto uma estrutura local similar. A estrutura local se mantém mesmo quando a rede mais abrangente - que articula diferentes áreas sob um mesmo dono ou vários donos entre si - passa por modificações. Não há uma rede geral, única, como se 
pensou que houvesse em meados dos anos 1980, nem jamais houve uma única liderança reconhecida em todas as áreas e por todos os "donos". Há contatos intermitentes entre "donos" que se dizem "amigos" e contatos regulares entre um "dono" e seus gerentes nas várias áreas, como também permanentes conflitos entre "donos".

Os primeiros “donos” do movimento já controlavam áreas desde o início dos anos 1970, mas as redes se constituíram a partir dos presidiários do início dos anos 1970 incursos na "Lei de Segurança Nacional" e de suas anteriores ligações, em suas áreas de origem, com assaltantes ou antigos donos de "boca de fumo". A continuidade entre os últimos "malandros" e "marginais" dos anos 1950 e 1960 e os atuais "vagabundos" deve ser buscada nas relações de vizinhança ou parentesco, mas também deve-se à "fama" que os primeiros obtinham junto aos adolescentes ("pivetes" e pequenos "marginais") nascidos nos anos 1950 e 1960, que buscaram imitar sua "valentia", sua "astúcia” ou que os transformaram em referência quanto ao estilo de vida. Foi, no entanto, a mediação da experiência dos assaltos a banco, na década de 1970, que levou a uma melhor organização das quadrilhas e a uma acumulação primitiva de capital, logo transferida para o mercado de drogas a varejo. Em seu brilhante romance etnográfico Cidade de Deus (1996), Paulo Lins recupera essa dimensão de continuidade, ao mostrar como os bandidos da "Cidade de Deus", por volta de 1977, tinham como referência os "marginais" tornados famosos pela imprensa na década de 1960 e começo de 1970, como "Charrão", do morro de São Carlos, e "Grande", da favela Macedo Sobrinho, na Lagoa.

O movimento proliferou com uma rede de capitalização baseada numa espécie de "empréstimo" com garantia em "vínculos de amizade" ou parentesco, mas sob a tensão do justiçamento sumário dos devedores. Mas foi a organização dos presidiários nos últimos anos da década de 1970 que fortaleceu (o nome dado a esse projeto foi esse mesmo, "fortalecimento") e tentou oligopolizar esse mercado a partir de 1983-1984. O Comando bancava tudo à pessoa que se dispunha a "botar o movimento" numa área nova: dava-lhe armas, contatos para a compra da droga, dinheiro. Em troca, ele pagaria regularmente com uma parte ponderável de seu lucro à "caixa" comum do Comando e respeitaria as regras de apoio mútuo, aliança contra adversários, respeito, apoio e "proteção" aos moradores locais e, principalmente, aos "amigos". Qualquer tentativa de fraudar a rede (“dar um banho"), em qualquer nível, seria punida com a morte.

No topo, a rede jamais foi inteiramente vertical, possuindo antes uma liderança "colegiada" informal, com uma parte controlando o "movimento" de dentro do presídio e a outra parte controlando de fora. O desenvolvimento da "desconfiança" entre a parte de "dentro" e a parte de "fora" e a ambição dos novos participantes em ampliar suas áreas constituem uma dimensão fundamental para a compreensão do fracasso da primeira rede (1984-1986) e a segmentação subseqüente (a partir de 1987), quando se estrutura o tráfico de armas e começam a chegar as primeiras armas leves (fuzis AK47 e ARl5). Mas, em geral, 
muitos aspectos, que restam investigar, parecem aproximar essa primeira rede da que organizava o "jogo do bicho" nas décadas de 1950 a 1970, com a sua divisão de áreas, sua hierarquia entre gerentes e vendedores, seus olheiros e pistoleiros, seu poder local e seu interesse político com a "proteção" dos moradores sob o seu raio de influência.

A busca de oligopolização do varejo por uma "cúpula", alcançada pelo jogo do bicho por volta de 1980, fez diminuir sensivelmente os efeitos de violência antes verificados nas disputas por "pontos" do bicho. A tentativa análoga, iniciada pelo Comando Vermelho na primeira metade dos anos 1980, não alcançou sucesso, e a prisão ou morte de suas principais lideranças, algumas delas relativamente "politizadas", deu lugar à continuidade da disputa por territórios que ainda se verifica hoje, com o conseqüente fracionamento das redes em novos "comandos" (reorganização do Terceiro Comando em 1990, "neutros” ou "independentes”, Comando Vermelho Jovem, Amigos dos Amigos etc.). Esse processo atingiu seu auge em 1994, ano em que a taxa de homicídios dolosos alcançou seu mais alto patamar no Rio de Janeiro (cerca de setenta por cem mil habitantes) e quando ocorreu intervenção federal no Estado. Desde então, a taxa declinou e estabilizou-se em torno dos 45 homicídios por cem mil habitantes, grande parte dos quais ainda vinculados às disputas nos mercados ilegais da cidade.

\section{O declínio dos "comandos"}

\section{e o incremento das "mercadorias políticas"}

Incidentes de grandes proporções, como a queima de ônibus em várias partes da cidade em duas ocasiões, o fechamento do comércio em alguns bairros e o ataque a instalações do governo estadual e da prefeitura, assinalaram, desde 2002, o início do declínio dos “comandos" no Rio de Janeiro. Todos esses eventos, na verdade, constituíam reações mais ou menos articuladas de dentro dos presídios ao aumento da repressão, à queda das vendas nas áreas sob invasão policial, ao aumento da extorsão policial ("arreglo, diz-se "arrêgo") e à prisão e morte de alguns dos principais nomes do tráfico na cidade. Além disso, a campanha da imprensa advertindo para o perigo nos morros, após o assassinato do jornalista Tim Lopes, da Rede Globo de Televisão por traficantes da Vila Cruzeiro, no chamado "complexo do Alemão", afastou grande parte da clientela de classe média das "bocas", no momento em que a moda de consumo de cocaína também declinava entre jovens de classe média, substituída em parte por drogas sintéticas caras, como o ecstasy.

O tráfico não desapareceu, mas o movimento diminuiu em muitas áreas, o que explica em parte o aumento dos assaltos, numa nova migração de jovens traficantes de volta ao roubo nas ruas. Em algumas áreas, o enfraquecimento do tráfico foi de tal monta que grupos organizados de policiais invadiram o local, expulsaram os grupos remanescentes de traficantes e instalaram-se como novos “donos", oferecendo compulsoriamente proteção aos moradores, sob pena de represálias. Mas antes que isso ocorresse, parte dos traficantes já vinha explorando 

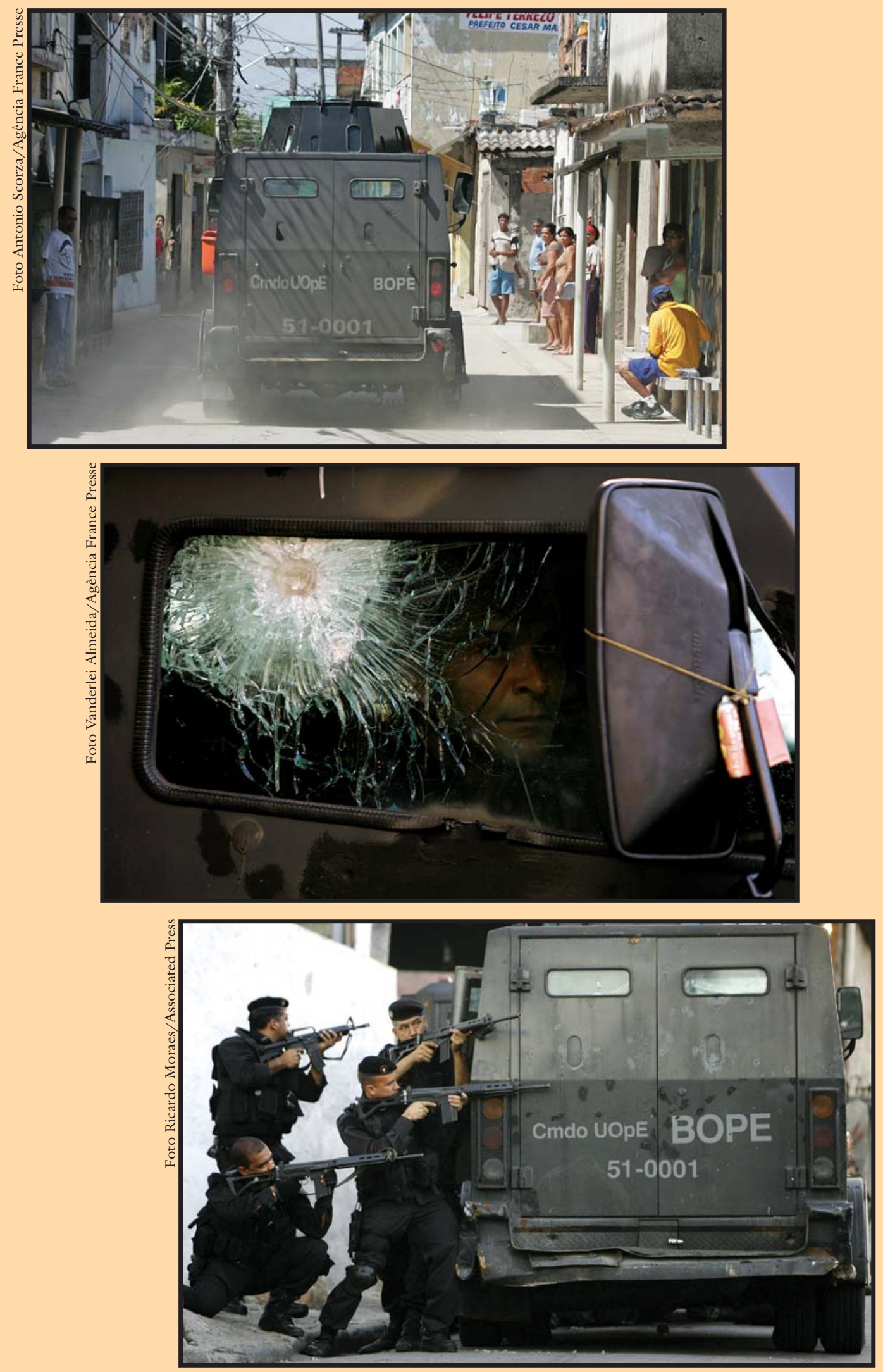
Manbã do dia 3 de maio de 2007, na Vila Cruzeiro, bairro da Penba, subúrbio do Rio de Janeiro. A equipe do Bope, o Batalhão de Operações Especiais da Policia Militar, desembarca de veículo blindado (Caveirão) na entrada da favela. Começa o tivoteiro. O soldado Wilson Santana Lopes, de 28 anos, é atingido ao atravessar a rua.
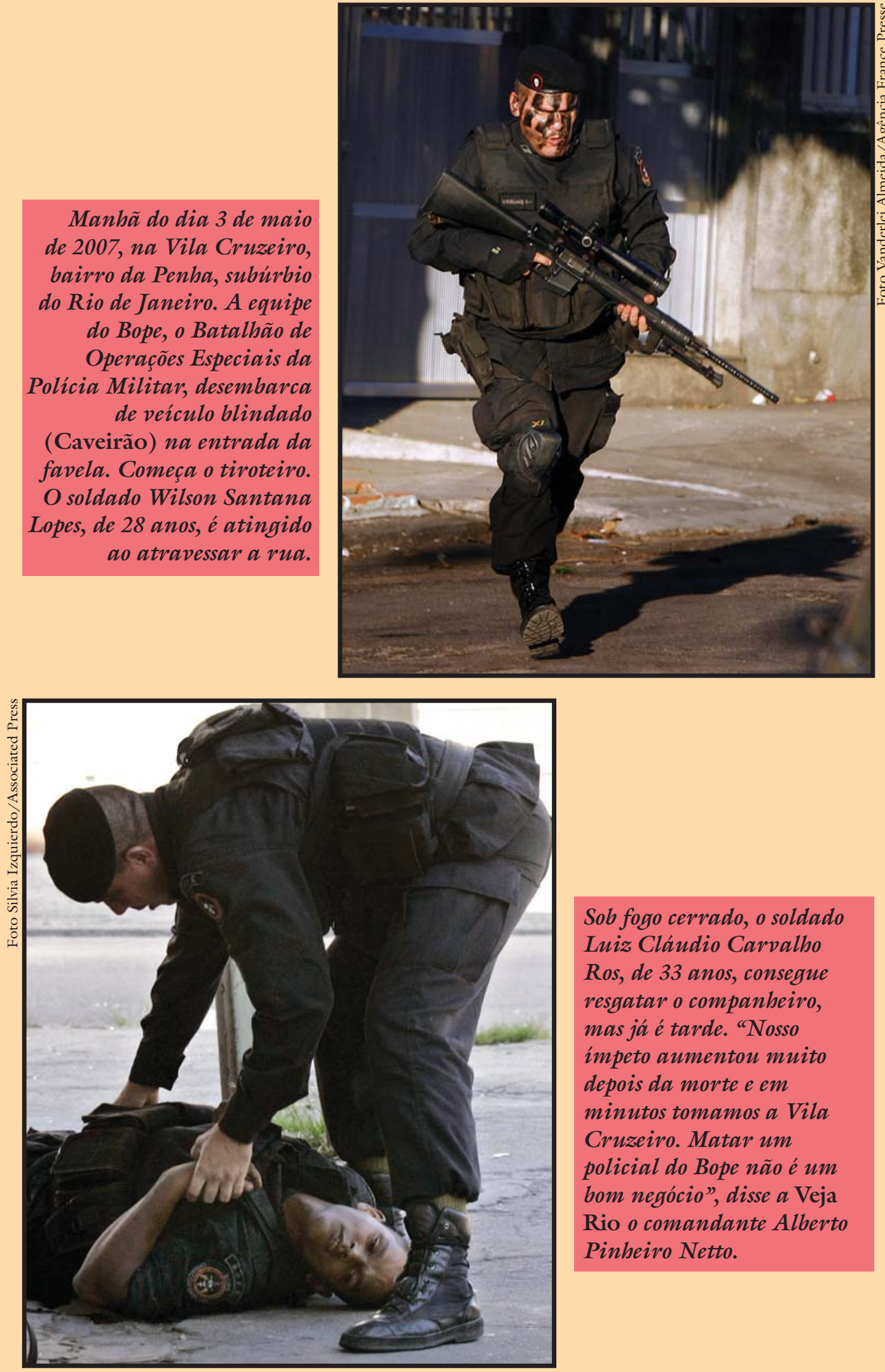

Sob fogo cerrado, o soldado Luiz Cláudio Carvalbo Ros, de 33 anos, consegue resgatar o companbeiro, mas já é tarde. "Nosso impeto aumentou muito depois da morte e em minutos tomamos a Vila Cruzeiro. Matar um policial do Bope não é um bom negócio", disse a Veja Rio o comandante Alberto Pinbeivo Netto. 
outras atividades ilegais, sinalizando para alternativas de exploração econômica baseadas no controle que exercem sobre suas áreas: serviços de televisão a cabo clandestinos, distribuição a varejo de gás em bujão, controle de frotas de "vans", cobranças de pedágio ou de contribuições compulsórias para a proteção da área contra outros criminosos. A quadrilha ganhava autonomia ante o tráfico de drogas, passava a complementá-lo, preparando-se para continuar a existir mesmo sem ele. Já era um indício do declínio do tráfico ante o volume de mortes e prisões dos últimos anos.

O mesmo se deu com o tráfico de armas, geralmente controlado por expoliciais. O volume de apreensões de armas de fogo no Rio de Janeiro nas últimas décadas alcançou números extraordinários e atingiu o varejo do tráfico exatamente pelo aumento do custo de reposição das armas perdidas. Embora atenuado, em parte, pelo "retorno" de parte das armas apreendidas ao tráfico, pela via das "mercadorias políticas", houve uma relativa estabilização nos conflitos entre quadrilhas a partir do final da década de 1990, que provavelmente contribuiu para a queda das taxas de homicídio doloso nos anos seguintes.

O aparecimento das chamadas "milícias", nome que a imprensa fez circular por toda a cidade a partir de 2006, é anterior ao atual fenômeno. Em pequenas favelas e conjuntos habitacionais onde há moradores policiais militares, esses conseguiram organizar-se seja para impedir a entrada do tráfico seja para expulsar ou matar assaltantes e outros jovens que ali pudessem ser identificados como criminosos. Na favela de "Rio das Pedras", por exemplo, o tráfico jamais conseguiu organizar-se, mesmo numa área com milhares de habitações. Sabia-se que policiais ofereciam e cobravam por "proteção" aos moradores e comerciantes há muitos anos. Na Zona Oeste e em parte da Zona da Leopoldina, em vários pequenos conjuntos habitacionais sucedia o mesmo, mas nem sempre com policiais moradores do local. O fenômeno das "milícias" ganhou maior visibilidade com as invasões organizadas de favelas e conjuntos habitacionais a partir de 2006 por grupos de trinta a quarenta policiais militares. Após afastarem os traficantes da área, instalavam ali de quatro a oito policiais que passavam a exigir uma "contribuição" dos moradores para a manutenção da "ordem". Assumiram, em seguida, algumas das atividades antes controladas pelo tráfico - como o cabeamento clandestino de TV por assinatura e a comercialização de bujões de gás.

A estratégia das "milícias" é nitidamente inspirada nas táticas do tráfico - reunião de traficantes de várias áreas para invadir uma área, depois a fixação de um pequeno grupo, bem armado, mantendo o controle do "território", sobre o qual exercem domínio e exploram atividades rentáveis. Não se devem confundir, entretanto, essas atividades de "proteção" com as de "vigilância privada", geralmente acionadas pelos próprios moradores junto a empresas licenciadas pela polícia. No caso das milícias, há inúmeros relatos de violência em relação a moradores que não concordaram em "contribuir" com os policiais para receberem "proteção". 
Os conflitos entre traficantes, milícia e polícia em algumas áreas da cidade têm provocado muitas mortes, mesmo entre moradores não vinculados a nenhum dos grupos. As associações de moradores locais, cujo controle passa a ser disputado pelo invasor, são as primeiras a sucumbir, e alguns de seus líderes, que resistem seja a um grupo seja a outro, são ameaçados de morte sem que a polícia ofereça nenhuma garantia para sua permanência em suas residências. Grupos da própria polícia, que antes extorquiam traficantes, apóiam a permanência das milícias em troca de comissões, quando não são eles mesmos os invasores. Não se pode entender as formas de organização da criminalidade no Rio de Janeiro se não se atentar para o importante papel cumprido por grupos de policiais - entre outros agentes do Estado - na manutenção do status quo. A sobreposição de dois mercados ilegais - um que oferece bens econômicos ilícitos e outro que o parasita impondo a troca de mercadorias políticas - constitui um dos eixos principais de reprodução ampliada da violência no Rio de Janeiro e de sua acumulação social.

Notas

l É imensa a bibliografia sobre as máfias italianas e as suas extensões norte-americanas. Desde os estudos já clássicos de Hess, Blok, Arlacchi até os recentes trabalhos de Catanzaro e Gambetta, este não é o lugar para citá-los, mesmo porque, em sua maioria, as questões aqui tratadas pouco têm a ver com as organizações criminosas de tipo mafioso. Para um artigo interessante sobre o tema, ver Cesoni (1995). Sobre a mesma questão nos Estados Unidos, ver Ianni \& Reuss-Ianni (1972) e Reuter (1983).

2 Sobre a economia subterrânea das drogas, ver Shiray (1994); sobre o "capitalismo clandestino", ver Godefroy \& Lascoumes (2004). Ver, sobre o mesmo tema, a coletânea organizada por Kokoreff et al. (2007).

3 A bibliografia sobre o jogo do bicho não é tão extensa quanto seria desejável. Entre os estudos mais importantes estão: Machado da Silva \& Figueiredo (1978); Pereira de Mello (1989); Chinelli \& Machado da Silva (1993); Soares (1993); Herschmann \& Lerner (1993); DaMatta \& Soárez (1999); Misse (1999); e Magalhães (2005).

4 Ver, a respeito, Lautier (1991); Mingione (1991); e Kopp (1997).

5 O período 1983-1987 compreende o primeiro governo de Leonel Brizola, geralmente acusado de negligência nessa área. Curiosamente, os dados indicam um volume muito maior de incriminação na área de entorpecentes em seu governo do que nos dois governos que o antecederam.

6 A frase de Lúcio Flavio dirigia-se, segundo muitos jornalistas da época, ao detetive Mariel Mariscot, que oferecia "proteção" a bicheiros e fazia extorsão a assaltantes de bancos.

7 Chamo de "mercadorias políticas" o conjunto de bens cuja troca se faz sob condição assimétrica, quase sempre compulsória e cujo valor incorpora igualmente custos econômicos e políticos. Sobre o conceito de "mercadorias políticas", ver Misse (2005). 
Referências bibliográficas

CESONI, M. L. L'économie mafieuse en Italie: à la recherche d'un paradigme. Déviance et Société, v.15, n.1, 1995.

CHINELLI, F.; MACHADO DA SILVA, L. A. O vazio da ordem: relações políticas e organizacionais entre as escolas de samba e o jogo do bicho. Revista Rio de Janeiro, ano 1, n.1, 1993.

DaMATTA, R.; SOÁREZ, E. Águias, burros e borboletas: um estudo antropológico do jogo do bicho. Rio de Janeiro: Rocco, 1999.

DOWDNEY, L. Crianças do tráfico. Rio de Janeiro: Sete Letras, 2003.

DUPREZ, D. et al. Carrières, territories et filières pénales: pour une sociologie comparée des trafics de drogues. Paris: OFDT, 2001.

GODEFROY, T.; LASCOUMES, P. Le capitalism clandestin. L'illusoire régulation des places "offshore". Paris: La Découverte, 2004.

HERSCHMANN, M.; LERNER, K. Lance de sorte. O futebol e o jogo do bicho na belle époque carioca. Rio de Janeiro: Diadorim, 1993.

IANNI, F.; REUSS-IANNI, E. A family business. Kinship and social control in organized crime. New York: Russel Sage, 1972.

KOKOREFF, M. et al. Économies criminelles et mondes urbains. Paris: Presses Universitaires de France, 2007.

KOPP, P. L'économie de la drogue. Paris: La Découverte, 1997.

LABROUSSE, A. Les drogues. Approche sociologique, économique et politique. Paris: La Documentation Française, 2004.

LAUTIER, B. et al. L'État et l'informel. Paris: L'Harmattan, 1991.

MACHADO DA SILVA, L.A.; FIGUEIREDO, A. A partir de um ponto do jogo do bicho. (Mimeogr.). 1978.

MAGALHÃES, F. Ganhou, leva, só vale o que está escrito. Experiências de bicheiros na cidade do Rio de Janeiro: 1890-1960. Rio de Janeiro, 2005. Tese (Doutorado em História) - Universidade Federal do Rio de Janeiro.

MELLO, M. P. de. A história social dos jogos de azar no Rio de Janeiro (1808-1946). Rio de Janeiro, 1989. Dissertação (Mestrado em Sociologia) - Instituto Universitário de Pesquisas do Rio de Janeiro.

MINGIONE, E. Fragmented societies. A sociology of economic life beyond the market paradigm. Oxford: Basil Blackwell, 1991.

MISSE, M. The organization of illegal markets: an economic analysis. U.S. Department of Justice, 1985.

As ligações perigosas: mercados ilegais, narcotráfico e violência no Rio. Contemporaneidade e Educação, Rio de Janeiro, ano 2, n.l, 1997.

. Malandros, marginais e vagabundos es a acumulação social da violência no Rio de Janeiro. Rio de Janeiro, 1999. Tese (Doutorado em Sociologia) - Instituto Universitário de Pesquisas do Rio de Janeiro.

. O delito como parte do mercado informal. In: SEMINÁRIO INTERNACIONAL “A VIOLÊNCIA NA AMÉRICA LATINA". Berlin: Freie Universitat, 2005. 
MISSE, M. Crime e violência no Brasil contemporâneo. Estudos de sociologia do crime e da violência urbana. Rio de Janeiro: Lúmen Juris, 2006.

REUTER, P. Disorganized crime: the economics of the visible hand. Cambridge: The MIT Press, 1983.

SHIRAY, M. (Ed.) Économie souterraine de la drogue. Paris: CNV, 1994.

SOARES, S. S. O jogo do bicho. A saga de um fato social brasileiro. São Paulo: Bertrand Brasil, 1993.

SOUZA, M. L. de. Redes e sistemas do tráfico de drogas no Rio de Janeiro: uma tentativa de modelagem. Anuário do Instituto de Geociências da UFRJ, v.19, 1996.

ZALUAR, A. Condominio do diabo. Rio de Janeiro: Editora da UFRJ, 1995.

. Integração perversa: pobreza e tráfico de drogas. Rio de janeiro: Editora da FGV, 2004.

RESUMO - Ao tratar da variedade de situações criminais que caem sob a qualificação de "Crime Organizado", este artigo apresenta a evolução das principais redes de mercados ilegais no Rio de Janeiro - o jogo do bicho, o tráfico de drogas, as "mercadorias políticas" -, para argumentar que a compra e venda de mercadorias políticas (extorsões e corrupção, venda de proteção, acesso a informações sobre operações policiais etc.) constitui uma das principais chaves para a compreensão da acumulação social da violência no Rio de Janeiro.

PALAVRAS-CHAVE: Mercados ilegais, Tráfico de drogas, Violência urbana, Crime Organizado, Rio de Janeiro.

ABSTRACT - By dealing with a variety of criminal situations that are qualified as "Organized Crime", this article presents the evolution of the main networks of illegal markets in Rio de Janeiro - "jogo do bicho" (the animal game - an illegal gambling pastime in Brazil), the drug trade, and "political commodities" -, in order to argue that the sales and acquisition of these political commodities (such as extortions, corruption, sales of protection, access to information on police operations etc.) constitutes one of the key concepts in understanding the social accumulation of violence in the city.

KErWORDS: Illegal markets, Drug trade, Urban violence, Organized Crime, Rio de Janeiro.

Michel Misse é professor associado do Departamento de Sociologia do Instituto de Filosofia e Ciências Sociais da Universidade Federal do Rio de Janeiro (UFRJ). Publicou recentemente Crime e violência no Brasil contemporâneo. Estudos de sociologia do crime e da violência urbana (Lúmen Juris, 2006). @ - m.misse@uol.com.br

Recebido em 4.9.2007 e aceito em 10.9.2007. 